\title{
A política na TV: questões identitárias e imaginário urbano
}

Maria da Conceição Golobovante - Doutora em Comunicação e Semiótica, professora da Pontifícia Universidade Católica de São Paulo.

Rosely Risuenho - Doutora em Comunicação e Semiótica, professora do Departamento de Educação da Universidade Federal do Pará.

\section{Resumo}

Este trabalho discute as relações entre mídia, política e identidade local com base nas campanhas televisivas de dois candidatos que concorreram ao segundo turno das eleições municipais para a prefeitura de Belém (PA) em 2004. Objetiva-se analisar o modo como a cidade é apresentada na retórica dos ideários propostos pelos candidatos e como as imagens do espaço público são editadas para justificar suas ações e produzir a adesão do espectador.

\section{Palavras-chave}

Comunicação, mídia regional, cidade, televisão, eleição, Amazônia.

\begin{abstract}
This work discusses the relations among media, politics and local identity based on television campaigns of two candidates who ran for Belém-PA City Hall second turn elections in 2004. The objective is to analyze how the city is presented in the rhetoric of ideas proposed by the candidates and how the images of public space are edited in order to justify their actions and get support from spectators.
\end{abstract}

\section{Keywords}

Communication, local media, television, election, Amazon. 
O Estado do Pará reflete, de forma aguda, as políticas de desenvolvimento concebidas ou implementadas na Amazônia nas três últimas décadas. Os grandes projetos agropecuários, hidrelétricos e de mineração, muitos localizados nesse Estado, determinaram uma política de infra-estrutura tecnológica e modelos de ocupação e de colonização voltados somente para a exploração dos recursos naturais e da mão-deobra local.

A depredação resulta de uma teia de múltiplos interesses das instituições e grandes corporações financeiras internacionais, da tecnocracia militar e civil e das elites regionais e nacionais. $O$ fato é que grande parte dos lucros, insumos e receitas decorrentes da expansão e do desenvolvimento econômico é desigualmente distribuída, acumulandose prioritariamente fora da região. Os principais beneficiados não arcam com o custo social e muito menos com o custo ambiental desse desenvolvimento, uma vez que ele é sustentado com recursos públicos.

$\mathrm{Na}$ região Norte, concentram-se as famílias com a segunda menor renda média do país, perdendo apenas para o Nordeste. O rendimento mediano mensal é $\mathrm{R} \$ 270,00$, bem abaixo do valor nacional, que é $\mathrm{R} \$$ 350,00 (dados do IBGE). A concentração de renda entre grupos locais elitizados e o aumento da exclusão social das classes sociais de baixa renda são retratos nacionais.

Entretanto, há que se reivindicar para a Amazônia - que dá muito mais do que recebe - um lugar de exceção. Sua secular condição de marginalização e de isolamento em relação às demais regiões do país produz ou agudiza a realidade das queimadas, do narcotráfico, dos conflitos de terra, da grilagem, da ecopirataria, da exploração equivocada do solo, da ação desordenada das madeireiras, do assassinato de lideranças políticas e do recente e acelerado processo de urbanização desordenada ("periferização da cidade" seria uma expressão mais adequada?).

Mais do que temas que dominam as manchetes da mídia nacional ou ganham visibilidade quando denunciados pela imprensa internacional, esses fatos geram insegurança, produzem desigualdades no interior do Estado, o que gera o fenômeno da migração de caboclos, ribeirinhos, lavradores, quilombados e indígenas para as capitais. Dados do censo IBGE (2000) indicam que cerca de 70\% das famílias residem nas cidades, e um peso muito grande recai sobre as duas maiores capitais (Belém e Manaus) que, juntas, aglutinam cerca de $30 \%$ da população da região amazônica. 
A divisão territorial em estruturas administrativas municipais, ocorrida sobretudo nos anos 80 do século XX, teve um impacto crescente na composição de grupos e arranjos de poder. Nos processos de mudança, há certamente uma modernização que se amplia, quer na administração, por meio de serviços, quer no acesso a novos mercados, potencializados pelas redes urbanas organizadas a partir da capital.

Metrópole com 1.280.000 habitantes, Belém está localizada no delta do rio Amazonas, na confluência dos rios Pará e Guamá. Assentada em terras baixas e atravessadas por pequenos rios e igarapés, a cidade tem um desenho urbano que conforma ainda hoje as divisões internas dos bairros, com seus terrenos altos ou aterrados e suas áreas alagadas, de baixadas, retrato e afirmação de hierarquias e processos de segregação social (Relatório MEGAM, 2005, p. 15).

Chama a atenção o padrão espacial singular de metropolização, resultante de um célere processo de periferização urbana, que se contrapõe, de maneira flagrante, à apropriação das áreas centrais, cada vez mais verticalizadas, por famílias de maior poder de aquisição e consumo. Em razão desses vetores de expansão, assiste-se ao estrangulamento das áreas centrais e de transição, bastante densificadas e congestionadas, pelas “invasões” (áreas ocupadas pela população de modo ilegal, mas legítimo).

Do ponto de vista político-partidário, passado o período de domínio de expoentes do coronelismo paraoara (lembremos políticos como Jarbas Passarinho, Hélio Gueiros e Jader Barbalho), cuja liderança baseava-se no tripé do populismo - força, carisma pessoal e centralização -, criou-se um vácuo recente na liderança política no Estado, pois os candidatos passaram a atuar muito mais como "profissionais" dos cargos que ocupam ou virão a ocupar, do que como mandatários e representantes da população regional.

Diante desse cenário, as campanhas na mídia televisiva para as eleições municipais de 2004, realizadas pelos candidatos à prefeitura de Belém, Ana Júlia Carepa (PT) e Duciomar Costa (PTB, Coligação do Povo), reproduzem o roteiro já consolidado de uma igualdade de classes sempre fictícia e de um sufrágio universal racionalmente duvidoso, uma

\footnotetext{
O projeto MEGAM (Estudo das Mudanças Socioambientais no Estuário Amazônico) foi um projeto multidisciplinar e multiinstitucional, realizado pelo Núcleo de Altos Estudos Amazônicos (NAEA) da Universidade Federal do Pará, que se estendeu de 1999 a 2005, sob a coordenação geral da professora doutora Edna Castro, contando com financiamento do PADCT/MC\&T e da Fundação Ford.
} 
vez que o "votante" singularizado nos discursos dos candidatos, que freqüentemente se dirigem a um "você, eleitor", age como a maioria, em nome de uma mínima representatividade comum, selando o contrato mínimo da ação política: um promete, o outro legitima.

Tomamos de empréstimo de Wolton (1990, p. 115 apud SILVA, 2005, p. 20) os "três aspectos democráticos da televisão de massa" para definir o formato de comunicação apresentada pelos candidatos: a polissemia da imagem, a incerteza quanto às condições de recepção e interpretação e o papel determinante do contexto na recepção, alargando as possibilidades de interpretação.

Interessa-nos particularmente o contexto, a que alude Wolton, ao qual nos referimos como espetacularização da cidade. O modelo de apresentação é clássico: manipula-se o imaginário de uma população de baixa consciência crítica, por meio da emissão de imagens em movimento travestidas em divertimento, mas, na verdade, marcadas por interesses eleitorais.

A fórmula parece-nos muito semelhante à citada por Juremir Machado Silva $(2005$, p. 22), quando comenta a política na TV de ficção: trata-se de um modo de atualizar um passado comum, de assentar sua identidade e os traços históricos e cotidianos que constituem o rosto de um povo e, paralelamente, de gozar do espetáculo.

Assim, as pessoas que aparecem circulando no espaço público estão em perfeita harmonia e parecem estar muito satisfeitas com os equipamentos urbanos, quando sabemos que, na Região Metropolitana de Belém, o processo de periferização ainda é a principal forma de expansão do tecido urbano, ou seja, há forte segregação socioespacial das frações populacionais de baixa renda, independentemente de sua localização (próxima ou distante) em relação ao núcleo central da cidade.

O crônico problema do "inchaço" das periferias é agravado sobretudo nas áreas das baixadas (partes da área urbana situadas no nível da planície, constantemente alagadas e sujeitas a inundações durante determinadas épocas do ano), cuja ocupação representa não apenas uma solução de emergência para moradia, como também uma estratégia de sobrevivência na grande cidade. Essa realidade provoca o colapso dos já deficitários serviços e equipamentos urbanos, com o prejuízo dos direitos sociais básicos e da qualidade de atenção à população.

Porém, o que se dá a ver nas campanhas é um povo em convivência e diálogo com a cidade. Para isso, recorre-se à presença de artistas locais (cantores de brega ou de ritmos regionais, atores consolidados de 
comerciais televisivos, poetas, escritores, folcloristas, radialistas, esportistas) em locações privilegiadas que têm como pano de fundo patrimônios históricos ou turísticos da cidade (Teatro da Paz, Catedral da Sé, Feliz Luzitânia e Estação das Docas) e ao depoimento de pessoas que gozam de prestígio profissional junto à população (médicos do Pronto-Socorro Municipal, comandantes da Polícia Militar ou do Corpo de Bombeiros, lideranças comunitárias) e geralmente "falam" em seus respectivos locais de trabalho.

Evidentemente, joga-se também com a retórica da beleza dos patrimônios públicos apresentados em harmonia com a população. Ao contrário das imagens de ruas asfaltadas da periferia ou de obras mais recentes, como pontes, escolas, viadutos etc., não se trata de uma obra associada aos gestores de partido $\mathrm{A}$ ou $\mathrm{B}$, mas do patrimônio histórico da cidade, o qual figura nos programas de ambos os candidatos como legítima testemunha da riqueza cultural da cidade.

O que nos interessa colocar em pauta é exatamente o "estranho fenômeno” que, segundo Maria Rita Kehl e Eugênio Bucci (2004, p. 67), faz pessoas, despojadas ou empobrecidas em sua subjetividade, dedicarse a cultuar a imagem de outras, destacadas pelas campanhas, o que demonstra claramente o consumo de imagens espetacularizadas de atores, cantores, esportistas e alguns (raros) políticos. Busca-se o que se perdeu: a dimensão humana e singular da história de vida de cada um.

Isso explica também, em parte, o efeito de adesão às imagens em panorama de crianças sorrindo, barcos deslizando no horizonte, donas de casa satisfeitas, artesãos em olarias e operários braçais carregando sorridentes sua carga. Tais imagens são reprisadas diariamente no Horário Eleitoral Gratuito, na TV ligada: um fluxo contínuo de imagens sobre as quais não é necessário pensar. Nesse caso, a visão de pessoas "simples" ou de "celebridades" locais escolhidas no que Belém "tem de melhor" no espaço público evita qualquer "esforço" de análise e de interpretação das propostas dos candidatos. Para que refletir ou decidir sobre o voto? O eleitor certamente vota em quem apresenta uma "miragem" mais bem acabada e mais próxima do modo como vê a si próprio: "esse é o ato da superficialidade, esse é o ato da irreflexão" (KEHL; BUCCI, 2004, p. 159).

Nesse sentido, como em qualquer estereótipo propagandístico, as pessoas são "ilustradas", mas não efetivamente "representadas". Por isso, acreditamos ter sido a força da "esperança de visibilidade" (do eleitor, 
de seu bairro, do seu time de futebol) - e menos a possibilidade de as promessas se transformarem em realidade - que acabou por definir a eleição em favor de Duciomar Costa. Vejamos o texto de abertura da campanha, no qual a cidade é enfatizada em um cenário paradisíaco, icônico e com o qual, ao mesmo tempo, pretende-se tocar na "alma" do povo e em seus legítimos anseios por "mudanças":

Existem duas Belém na vida da gente. Uma é aquela que a gente leva com a gente dentro do peito aonde quer que a gente vá. É a Belém mais linda, mais amiga. Que recebe a gente cedinho com sorriso e com fartura. É a Belém que se despede com um abraço todos os dias, refletindo o seu calor e o seu amor nas águas do rio Guajará. Belém da gente que trabalha com vontade, que constrói o seu futuro, mas preserva as conquistas do passado e se espelha em sua própria história.

A outra Belém é aquela que a gente tá vendo todos os dias nas ruas, nas esquinas, de dia e de noite. É a Belém que entristece a alma da gente, que faz nosso coração ficar apertado. Essa Belém faz promessa e não perde a fé, mesmo que a fé no que virá [referência à assinatura da campanha do prefeito de Edmilson Rodrigues, do PT] nunca tenha vindo.

Ab! Que bom vai ser quando a Belém que a gente traz dentro do peito for a mesma Belém que a gente vai encontrar nas ruas também. E isso não demora para acontecer. Porque Belém quer mudar. Belém vai mudar (grifos nossos).

Note-se que a propaganda política é realizada por profissionais, geralmente oriundos das áreas de jornalismo e publicidade, cujo saber especializado, fora do período eleitoral, é remunerado por empresas e veículos comerciais. A lógica do mercado determina a formação e a atuação desses profissionais que, ao aplicar sua experiência à produção de uma campanha política (a dedicação integral e o desgaste fazem com que os valores dessa prestação de serviço alcancem, por vezes, cifras milionárias), levam consigo os mecanismos intrínsecos da sua experiência profissional. Ao contrário das afirmações apressadas, que vêem nesse trabalho a ocasião propícia para se "vender" políticos como se fossem sabonetes, ainda mais no caso de campanhas televisivas, o que se constata é um complexo acionamento de saberes interdisciplinares para, a depender do tipo de eleição, da área geográfica e do público a ser atingido, poder explorar ao máximo os recursos da mídia audiovisual. O público telespectador, embora destinatário dos conteúdos televisivos, nunca é 
convocado a participar da sua produção. Mas esse é um paradigma da produção televisual como um todo, qualquer que seja, com exceção das raras experiências de TV regionais, como o modelo de Pauta Cidadã da TVE-RJ (SOUSA, 2006, p. 105) .

A propaganda, do ponto de vista processual, envolve um mecanismo complexo de construção ideológica. O "emissor", grupo que promove a difusão das idéias do candidato, realiza a "elaboração" da sua ideologia para que as idéias nela contidas pareçam corresponder àqueles interesses. Em seguida, há uma processo de "codificação", pelo qual transformamse as idéias em mensagens que atraiam a atenção e sejam facilmente compreensíveis e memorizáveis por um grupo de receptores, que, por não terem acesso ao modo de produção, ficam impossibilitados de construir outra ideologia que os oriente em sentido contrário ao do emissor. A partir daí, as mensagens são emitidas através da "difusão" que, no caso da televisão, é uma difusão audiovisual e instantânea (GARCIA, 1985, p. 28-29).

No que concerne à ponta da recepção, segundo Sarlo (2004, p. 121), os setores populares não têm mais obrigações do que os letrados: não é lícito que sejam mais espertos, nem mais rebeldes, nem mais persistentes, nem que vejam com mais clareza, nem que representem outra coisa senão eles mesmos. Mas, em contraste com as elites econômicas e intelectuais, eles dispõem de uma quantidade menor de bens materiais e simbólicos, estão em condições de usufruto cultural piores e têm menores possibilidades de praticar escolhas não condicionadas pela pobreza da oferta ou pela escassez de recursos materiais e instrumentos intelectuais; em geral, demonstram mais preconceitos racionais, sexuais e nacionais do que os intelectuais, que aprenderam a ocultá-los ou mesmo a eliminá-los.

A forma mais utilizada na elaboração das ideologias é a universalização. As idéias que se referem, na realidade, aos interesses particulares das elites são apresentadas como propostas universais que visam atender a todos e satisfazer as necessidades da maioria. No Pará, isso vem atrelado ao ufanismo característico cantado em jingles que assumem os ritmos e as cores locais. A música aciona diferentes ritmos, dos mais tradicionais, como o carimbó, aos mais maciçamente difundidos, como a lambada e o calypso.

A propaganda dissemina, de forma persuasiva, para toda a sociedade, as idéias de um determinado grupo. Depois de emitidas, ou veiculadas, elas passam a ser retransmitidas, direta ou indiretamente, no seio das diversas instituições sociais, ampliando e reforçando o processo 
de difusão. Nesse sentido, as mensagens propagandísticas interagem com os produtos audiovisuais (jornais, novelas, programas) que compõem a programação da TV, interferindo na configuração e no ritmo do fluxo a que assistimos (RAMOS, 1995, p. 69).

Os produtores da campanha do PT esforçam-se para apresentar uma versão mais pedagógica, educativa, que demonstre os "feitos" de oito anos de mandato do até então prefeito Edmilson Rodrigues, entretanto, o povo quer sempre se divertir, poder identificar-se com os personagens (depoimentos, cenas de alegria) e obter também um pouco de informação. $O$ real pode ser mostrado, desde que esteja atrelado ao "descaso" do PSDB no comando do governo do Estado.

Esse quadro faz sentido quando pensamos que, tal como formula Baudrillard (1990, p. 21), uma escolha não é mais determinada pela sua utilidade, no caso, pela competência do candidato. Reconhece-se o valor do lúdico. A sociedade da utilidade está em vias de tornar-se obsoleta. A imagem do homem sentado e contemplativo, em um dia de greve, sua tela de televisão vazia, valerá um dia como uma das mais belas imagens da antropologia do século XX.

Nada temos contra o divertimento e estamos de acordo com Juremir Machado quando afirma que o prazer funda as estratégias populares de reação à dominação que as asfixia. $\mathrm{O}$ problema existe quando essa necessidade de divertimento é espetacularizada como a forma predominante de representação, o que, no caso de Belém, chega a ser levado ao limite máximo de internalização e de identificação da população, que se deixa cegar pelas repetidas imagens de manifestações locais do "ser paraense", do pertencer a uma cultura regional. O encantamento também faz parte de outra tradição, que liga o mistério e o sortilégio dos relatos míticos, enigmas e encantos para nomear os hermetismos culturais da "metrópole da Amazônia".

Em outro pólo, na campanha de Duciomar Costa (PTB), candidato que teve o apoio do governador do Estado Simão Jatene (PSDB), o povo paraense movimenta-se freneticamente. Seu discurso desqualifica as "utopias" dos pseudo-intelectuais e mostra uma população que tenta sobreviver com seus próprios meios, mesmo ilícitos, traçando um perfil esquemático de um "tipo ideal urbano", sobre o qual se desdobra uma série de tipos intermediários. Assim, camelôs, ambulantes e feirantes, por exemplo, entram como se pertencessem a uma mesma categoria e, logicamente, com o mesmo valor, amparados na retórica de que todos 
são trabalhadores, sem que se discuta o tema do mercado informal. Aliás, a retórica imagética apela para o resultado das linhagens miscigenadas que se inscreve num modo de habitar a cidade.

O Círio de Nazaré, a maior festa religiosa do Brasil é presença obrigatória em todos os comerciais do horário eleitoral gratuito, alegoriza o elogio cristão do sofrimento emancipador. Ou seja, o mesmo povo que é capaz dos maiores sacrifícios religiosos (pagar promessas, segurar na corda, suportar o calor e a compressão humana dos devotos) dá duro, reivindica "saúde, transporte, lazer, respeito, educação e habitação", mas fundamentalmente é movido pelo "amor" a Belém.

Contando com o apoio dos movimentos sociais organizados, a campanha de Ana Júlia (PT) enaltece, por meio de imagens hiper-realistas, o progresso infra-estrutural das ruas e equipamentos populares de lazer (Aldeia Cabana, Espaço Ver-o-Rio, entre outros), produtores de bemestar para a população mais empobrecida. Esse é o lado feérico, festivo, da alteração da imagem pública, mas também se procura maquiar as mazelas e os detritos que o decantar do mandato de oito anos do prefeito petista Edmilson Rodrigues não consegue esconder.

Duciomar, apoiado na promessa de ter e de ser "sempre mais", tornou-se um vitorioso após o segundo turno. A enorme massa de semteto e sem-emprego acreditou que a Coligação do Povo poderia oferecerlhe as chances de ter mais bens e de ser mais respeitada. Dentre as "estratégias de atração", ou seja, as estratégias destinadas a criar a demanda do candidato por meio da propaganda, destaca-se a letra do "hino" inicial da campanha de Duciomar, que enfatiza o enraizamento e a devoção do povo a Belém:

Um sonho bom em Belém do Pará é essa vontade de mudar, é a certeza de ir em frente que está no coração dessa gente.

A paixão por esse lugar espelha a honra de lutar.

É a história de um povo que acredita no trabalho que se vê com a vontade de vencer pelo futuro do nosso chão Sou Belém, sou Pará, sou Duciomar.

Se Duciomar explora o clichê de estar no "coração", Ana Júlia contra-ataca representando a "beleza de uma flor" (candidata mulher, feminina, encarnando a figura maternal daquela que cuida, zela):

Belém, vou te amar pra sempre assim, quero ver você crescer sempre tão linda. 
Contemplar o sol do Ver-o-Rio e ver o teu luar.

$\mathrm{Na}$ beleza de uma flor, Minha cidade cuidada, tratada com carinho por alguém que confio

Por isso fiz minha opção: sou Ana júlia, o melhor para Belém.

Nos dois casos, a cidade como representação física e social está associada a uma abertura, ao cenário pelo qual circula a palavra, oferecendo uma série de perspectivas. Sem dúvida, como enfatizam Martín-Barbero e Rey (2001, p. 91), a comunicação permite a visibilidade, na medida em que abre o espaço da deliberação pública, expõe os temas controversos e suas diferentes interpretações e aumenta a quantidade e, sobretudo, a qualidade das formas de acesso ao debate social.

Nem sempre é assim, certamente. A auto-referencialidade exacerbada não apenas distorce as informações, mas também consolida um "nós" que é, ao nosso ver, segregacionista e até mesmo autoritário. Não se trata de formas mais híbridas de etnias, mas de atitudes exclusivistas, de reafirmação das raízes culturais, sem que se configure uma atitude de resistência ao processo de homogeneização global (HALL, 2003, p. 95). A tensão entre o visível e o ocultado da cidade, com realidades construídas em versões, é evitada justamente para afastar os eleitores do mundo das decisões. A identidade do belenense/paraense (não há aqui uma separação de pertencimento) é construída ou reforçada nas campanhas por meio de generalizações afetadamente negligentes, como uma ilusão cenográfica (exibição de sorrisos, da culinária, das danças folclóricas), que alimenta um bairrismo intransigente e desnecessário.

O sentido mais vivo de identidade é perdido, deixa-se de participar da criação de agendas públicas em que circulem os temas caros à população e em que se transmitam perspectivas de interpretação não tradicionais do "ser" paraense, como sujeito num universo de diferenças materiais e simbólicas, que assume a responsabilidade e o prazer de habitar Belém, opção que a retórica político-partidária escravocrata ainda é incapaz de formular.

\section{REFERÊNCIAS}

BAUDRILLARD, Jean. La transparence du mal: essais sur les phénomènes extrêmes. Paris: Galilée, 1990.

GARCIA, Nelson. Propaganda ideológica. 4. ed. São Paulo: Brasiliense, 1985.

HALL, Stuart. A identidade cultural na pós-modernidade. Rio de Janeiro: DP\&A, 2003. 
KEHL, Maria Rita; BUCCI, Eugênio. Videologias. São Paulo: Boitempo, 2004.

MARTÍN-BARBERO, Jesus; REY, Germán. Os exercícios do ver. São Paulo: SENAC, 2001.

MACHADO, Juremir. A política na TV de ficção. Revista Comunicação, Mídia e Consumo, São Paulo, v. 2, n. 3, p. 11-24, mar. 2005.

RAMOS, José Mario Ortiz. Televisão, publicidade e cultura de massa. Petrópolis: Vozes, 1995.

SARLO, Beatriz. Cenas da vida pós-moderna: intelectuais, arte e videocultura na Argentina. Rio de Janeiro: UFRJ, 2004.

SILVA, Juremir Machado da. A política na TV de ficção. Revista Comunicação, Mídia e Consumo, São Paulo, v. 2, n. 3, p. 11-24, mar. 2005. SOUSA, Cidoval Morais de (Org.). Televisão regional. Rio de Janeiro: Sotese, 2006. 
